\title{
Atitudes dos/as estudantes universitários/as face à homossexualidade: tradução e validação de uma escala de medida
}

\section{University students' attitudes towards homosexuality: translation and validation of a measurement scale}

\author{
Regina Ferreira Alves*
}

\begin{abstract}
RESUMO
O reconhecimento oficial da homossexualidade, impulsionado pela legalização da união entre casais do mesmo sexo em Portugal, deveria diminuir as atitudes e os comportamentos homonegativos e, consequentemente, as perseguições a indivíduos não heteronormativos. Com base nesse pressuposto, realizou-se este estudo, cujo objetivo é avaliar as atitudes dos/as estudantes universitários/as dos mestrados em ensino e em educação $(\mathrm{N}=151)$ face à homossexualidade. Para tal, foi traduzida e adaptada socioculturalmente uma escala de atitudes face às lésbicas e aos homens gays (Attitudes Toward Lesbians and Gay Men - ATLG). Os resultados obtidos mostraram baixos níveis de preconceito dos/as estudantes universitários/as relacionados com a orientação sexual, em particular dos inquiridos do sexo feminino. No entanto, apesar de assumirmos que as respostas dos inquiridos estariam condicionadas pelo desejo social de baixar os níveis de preconceito, verificou-se discursos incongruentes quando se tratou de questões como a homoparentalidade ou a homofiliação, momento em que os inquiridos assumiram uma atitude mais homonegativa. As conclusões deste estudo mostraram a necessidade de criar condições para que os estudantes universitários, durante a sua formação, refletissem sobre as suas atitudes face à homossexualidade. Além de aprender a desenvolver processos educativos que incluam a promoção do respeito e a convivência saudável com a diversidade sexual e a defesa dos direitos humanos.
\end{abstract}

Palavras-chave: Homonegatividade. Homossexualidade. Homofobia. Estudantes universitários.

* Universidade do Minho. Instituto de Educação. Braga, Portugal. E-mail: rgnalves@gmail. com. https://orcid.org/0000-0001-7189-5487. 


\begin{abstract}
The official recognition of homosexuality, driven by the legalization of marriage between same-sex couples in Portugal, should have reduced homonegative attitudes and behaviors and, consequently, persecution of non-heteronormative individuals. Based on this assumption, this study was carried out with the objective of evaluating the attitudes of university students $(\mathrm{N}=151)$ regarding homosexuality. To that end, a scale of attitudes towards lesbian and gay men ("The Attitudes Toward Lesbians and Gay Men Scale" - ATLG) has been translated and socioculturally adapted. The results obtained showed low levels of prejudice of university students related to sexual orientation, especially from female respondents. However, although we assume that the respondents' answers may have been conditioned by the social desirability of lowering their levels of prejudice, there were incongruous discourses when dealing with issues such as homoparentality or homophilia, towards which respondents took a more homonegative attitude. The conclusions of this study have showed the need to create conditions for university students, during their education, to reflect on their attitudes towards homosexuality, as well as develop educational processes that include the promotion of respect and healthy coexistence with sexual diversity and the defense of human rights.
\end{abstract}

Keywords: Homonegativity. Homosexuality. Homophobia. University students.

\title{
Introdução
}

O reconhecimento oficial da homossexualidade, impulsionado pela legalização da união entre casais do mesmo sexo em Portugal, deveria favorecer e certamente diminuir os comportamentos homonegativos e, consequentemente, as perseguições a indivíduos com uma orientação sexual não normativa. Ao mesmo tempo, a aceitação legal das uniões homoafetivas deverá encorajar mais homens gays e mulheres lésbicas a assumirem a sua orientação sexual e não irá "criar" mais homossexuais. A legalização somente tornou mais justa a vida das pessoas que já vivem esta orientação sexual de forma clandestina e tornou possível assumirem-se pelo que são, diminuindo as suas angústias.

O discurso social, quanto à aceitação da diversidade sexual, tornou-se "moda", refletindo-se nos discursos extremamente multifacetados que nos chegam pelos media ou pelas vozes que circulam no local. No entanto, apesar das atitudes desejáveis socialmente ou ditas politicamente corretas, sabe-se que 
existe o chamado preconceito sexual, a homofobia ou a homonegatividade. $\mathrm{Ou}$ seja, se, por um lado, "a adopção de uma identidade gay ou lésbica é considerada uma orientação viável e saudável, por outro lado, existem ainda preconceitos e desinformação persistente sobre a homossexualidade com diferentes resultados e consequências" (NOGUEIRA; OLIVEIRA, 2010, p. 10).

A homonegatividade pode ser entendida como uma "espécie de medo irracional que os heterossexuais poderiam experienciar relativamente às pessoas homossexuais, bem como o autodesprezo que lésbicas e gays poderiam sentir por si próprios" (GATO et al., 2011, p. 141). No mesmo sentido, Junqueira $(2009$, p. 3) definiu a homofobia como "um conjunto de emoções negativas, que costuma produzir ou vincular-se a preconceitos e mecanismos de discriminação e violência contra pessoas homossexuais, bissexuais e transgéneros".

Os comportamentos homofóbicos, homonegativos, homossexistas ou homopreconceituosos dirigem-se contra todas aquelas pessoas que se afastam da heteronormatividade, ou seja, comumente aqueles homens que sentem desejo e atração sexual e emocional por outro homem e aquelas mulheres que sentem esse mesmo desejo e atração sexual e emocional por outras mulheres. Esses comportamentos são considerados hostis, caracterizando as orientações sexuais que "fogem à norma" como promíscuas.

\section{Método}

\section{Objetivos}

O objetivo deste estudo passa por compreendermos quais são os níveis de homonegatividade que os futuros profissionais nas áreas de ensino e educação apresentam, ou seja, avaliar as atitudes dos/as estudantes universitários/as dos mestrados em ensino e em educação face às mulheres lésbicas e aos homens gays.

\section{Instrumentos}

De modo a atingir os objetivos aos quais nos propusemos, recorremos ao inquérito por questionário, no qual incluimos a escala de atitudes face às mulheres lésbicas e aos homens gays - ATLG (HEREK, 1998), composta por 20 itens, sendo os 10 primeiros relativos às mulheres lésbicas e os 10 restantes direcionados para os homens gays. As respostas a cada item são atribuídas em função de uma escala de Likert de nove pontos, que varia do discordo totalmente (1) ao concordo totalmente (9), na escala original, mantendo-a neste estudo. O 
autor refere que esses itens podem ser utilizados em conjunto ou individualmente em duas subescalas - atitudes face às mulheres lésbicas (ATL) e atitudes face aos homens gays (ATG). A soma das pontuações das subescalas podem variar de 10 a 90 (a escala ATLG pode variar entre 20 e 180), sendo que, quanto maior o valor, maiores serão as atitudes homonegativas, para tal as pontuações atribuídas a alguns itens foram invertidas. No entanto, apesar da possibilidade de utilizar as somas das pontuações atribuídas a cada subescala, optou-se por calcular o valor médio das pontuações atribuídas por cada estudante universitário/a em cada uma das subescalas, variando de 1 (mínimo de homonegatividade) a 9 (máximo de homonegatividade), atendendo que a pontuação de alguns itens, aquando da análise dos dados, foi invertida, de modo que os valores mais altos correspondessem a atitudes mais negativas face à homossexualidade (itens 2 , $4,7,11,15,17$ e 20). Essa escala mostrou um alto nível de consistência interna (valor de alfa $=.905$ ), da mesma forma para a subescala de homonegatividade face às mulheres lésbicas, com um Alfa de Cronbach de .779 e de .882 para a subescala de homonegatividade face aos homens gays. Com vista a aprofundar a análise dos resultados, através dos valores médios de cada subescala, foram criadas categorias recorrendo ao ponto de corte \pm 1 desvio-padrão de cada uma. Desse modo, na subescala das atitudes face às mulheres lésbicas (ATL) $(M=$ $2.27, \mathrm{DP}=1.174$ ), as atitudes com valores $<1.10$ foram consideradas levemente negativas, entre 1.10 e 3.44 moderadamente negativas e $>3.44$ extremamente negativas. De igual modo, na subescala das atitudes face a homens gays (ATG) $(M=2.78, \mathrm{DP}=1.431)$, as atitudes com valores $<1.35$ foram consideradas levemente negativas, entre 1.35 e 4.21 moderadamente negativas e $>4.21$ extremamente negativas.

\section{Procedimentos}

Os inquéritos por questionário foram distribuídos aos/às estudantes universitários/as em sala de aula, tendo o processo de preenchimento demorado cerca de 15 minutos. Antes de iniciado o preenchimento, os/as estudantes universitários/as foram esclarecidos/as relativamente à finalidade e aos objetivos do estudo, à não obrigatoriedade de resposta, assim como à garantia de anonimato.

Os dados obtidos foram analisados com o recurso ao software SPSS - Statistical Package for the Social Sciences - através do qual, numa primeira fase, se procedeu à análise descritiva ou distribuição de frequências para as diferentes variáveis do questionário. E, de seguida, as diferenças nos níveis de homonegatividade em função das características sociodemográficas foram analisadas através da utilização da análise univariada da variância (ANOVA) e t-student. 


\section{Amostra}

No total participaram 151 estudantes universitários/as, de ambos os sexos, do primeiro ano dos mestrados em ensino e em educação. Através da observação da Tabela I, é possível verificar que $29.8 \%(\mathrm{~N}=45)$ eram do sexo masculino e $70.2 \%(\mathrm{~N}=106)$ do sexo feminino, tendo todos/as os/as inquiridos/as respondido a esta questão.

Relativamente ao estado civil, observa-se que $79.5 \%(\mathrm{~N}=120)$ era solteiro/a, $17.2 \%(\mathrm{~N}=26)$ casado/a ou vivia em união de facto e a restante percentagem era divorciado/a ou separado/a $(2.7 \%, \mathrm{~N}=4)$ e viúvo/a $(0.7 \%, \mathrm{~N}=1)$.

No que concerne à orientação sexual, a maioria dos estudantes universitários $(95.1 \%, \mathrm{~N}=137)$ declarou ser heterossexual, $2.8 \%(\mathrm{~N}=4)$ indicaram ter uma orientação homossexual (gay/lésbica) e $2.1 \%(\mathrm{~N}=3)$ referiram ser bissexuais.

TABELA I - FREQUÊNCIA E PERCENTAGEM NA DISTRIBUIÇÃO DO SEXO, DA IDADE, DO ESTADO CIVIL E DA ORIENTAÇÃO SEXUAL

\begin{tabular}{lrrr}
\hline Variável & & f & \% \\
\hline Sexo & & 45 & 29.8 \\
Masculino & & 106 & 70.2 \\
Feminino & Total & $\mathbf{1 5 1}$ & $\mathbf{1 0 0 . 0}$ \\
& & & \\
Idade (anos) & & 50 & 36.0 \\
18-22 & 40 & 28.8 \\
$23-27$ & & 22 & 15.8 \\
$28-32$ & & 16 & 11.5 \\
$33-37$ & & 11 & 7.9 \\
$>38$ & Total & $\mathbf{1 3 9}$ & $\mathbf{1 0 0 . 0}$ \\
& & & \\
Estado Civil & & 120 & 79.5 \\
Solteiro/a & & 26 & 17.2 \\
Casado/a / União de facto & & 1 & 0.7 \\
Viúvo/a & & 4 & 2.7 \\
Divorciado/a / Separado/a & & $\mathbf{1 5 1}$ & $\mathbf{1 0 0 . 0}$ \\
& Total & & \\
Orientação Sexual & & 4 & 2.8 \\
Homossexual (gay/lésbica) & & $\mathbf{1 3 7}$ & 2.1 \\
Heterossexual & & $\mathbf{1 0 0 . 0}$ \\
Bissexual & &
\end{tabular}

FONTE: elaboração própria, adaptado (ALVES, 2013). 
A Tabela II mostra o número de estudantes universitários/as e a respetiva percentagem por cada um dos mestrados em ensino e em educação. Da análise desta tabela é possível verificar que o número de inquiridos/as por curso de mestrado é quase equivalente, sendo que o curso de mestrado com um menor número de estudantes universitários/as inquiridos/as foi o de Ensino de História e de Geografia no $3^{\circ}$ Ciclo do Ensino Básico e no Ensino Secundário $(\mathrm{N}=8)$ e aquele que registrou um maior número de inquiridos/as os de Ensino de Música $(\mathrm{N}=18)$ e Educação - Formação, Trabalho e Recursos Humanos $(\mathrm{N}=18)$.

\section{TABELA II - FREQUÊNCIA E PERCENTAGEM DOS/AS ESTUDANTES UNIVER-} SITÁRIOS/AS POR MESTRADO

\begin{tabular}{|c|c|c|}
\hline & $\mathbf{f}$ & $\%$ \\
\hline Ensino de Educação Física nos Ensinos Básico e Secundário & 12 & 7.9 \\
\hline Ensino de Música & 18 & 11.9 \\
\hline Educação - Mediação Educacional e Supervisão na Formação & 13 & 8.6 \\
\hline $\begin{array}{l}\text { Ensino de Português no } 3^{\circ} \text { Ciclo do Ensino Básico e Ensino } \\
\text { Secundário e de Espanhol nos Ensinos Básico e Secundário }\end{array}$ & 15 & 9.9 \\
\hline $\begin{array}{l}\text { Ensino de Inglês e de Espanhol no } 3^{\circ} \text { Ciclo do Ensino Básico e no } \\
\text { Ensino Secundário }\end{array}$ & 11 & 7.3 \\
\hline $\begin{array}{l}\text { Ensino de Biologia e de Geologia no } 3^{\circ} \text { Ciclo do Ensino Básico e no } \\
\text { Ensino Secundário }\end{array}$ & 12 & 7.9 \\
\hline Educação - Formação, Trabalho e Recursos Humanos & 18 & 11.9 \\
\hline $\begin{array}{l}\text { Ensino de História e de Geografia no } 3^{\circ} \text { Ciclo do Ensino Básico e no } \\
\text { Ensino Secundário }\end{array}$ & 8 & 5.3 \\
\hline Ensino de Filosofia no Ensino Secundário & 10 & 6.6 \\
\hline $\begin{array}{l}\text { Ensino de Matemática no } 3^{\circ} \text { Ciclo do Ensino Básico e no Ensino } \\
\text { Secundário }\end{array}$ & 11 & 7.3 \\
\hline Ensino de Informática & 11 & 7.3 \\
\hline Educação - Educação de Adultos e Intervenção Comunitária & 12 & 7.9 \\
\hline Total & 151 & 100.0 \\
\hline
\end{tabular}

FONTE: elaboração própria, adaptado (ALVES, 2013).

Na Tabela III, apresentamos os dados relativos à religião e à religiosidade apontados pelos/as estudantes universitários/as inquiridos/as. Assim, verificamos que a maioria indicou ser de religião católica $(\mathrm{N}=123)$. No que concerne à religiosidade, avaliada numa escala de 1 (nada religioso/a) a 7 (muitíssimo religioso/a), a média geral da religiosidade foi de $3.89(\mathrm{DP}=1.518)$. 
TABELA III - FREQUÊNCIAE PERCENTAGEM DADISTRIBUIÇÃO DAS MÉDIAS DE RELIGIOSIDADE PELAS DIFERENTES RELIGIÕES

\begin{tabular}{lrr}
\hline Religião & Média & DP \\
\hline Católica $(\mathrm{N}=123)$ & 4.27 & 1.222 \\
Outra não Cristã $(\mathrm{N}=2)$ & 4.50 & .707 \\
Outra Cristã $(\mathrm{N}=2)$ & 3.50 & .707 \\
Sem religião $(\mathrm{N}=19)$ & 1.42 & .961 \\
$\quad$ Total $(\mathbf{N}=\mathbf{1 4 6})$ & 3.89 & 1.518 \\
\hline
\end{tabular}

FONTE: elaboração própria, adaptado (ALVES, 2013).

Cruzando a distribuição do grau de religiosidade com as diferentes religiões, observamos que os/as católicos/as referiram ser moderadamente religiosos/as $(\mathrm{M}=4.27, \mathrm{DP}=1.222)$ e os/as estudantes universitários/as sem religião assumiram-se como nada religiosos/as $(\mathrm{M}=1.42, \mathrm{DP}=.961)$.

\section{Resultados}

Homonegatividade face às mulheres lésbicas e aos homens gays

A Tabela IV mostra os resultados para cada um dos itens da escala de homonegatividade (ALTG), através do qual verificamos que os itens nos quais as pontuações atribuídas são mais elevadas, demonstrando um maior nível de homonegatividade, são: "Os casais de homens homossexuais devem ser autorizados a adotar crianças do mesmo modo que os casais heterossexuais" $(\mathrm{M}=$ $4.42, \mathrm{DP}=2.827) \mathrm{e}$ "Eu não ficaria muito chateado se soubesse que um filho meu é homossexual" $(\mathrm{M}=4.38, \mathrm{DP}=2.808)$. Da mesma forma, é possível verificar que os itens com as médias de pontuações mais baixas, revelando uma menor homonegatividade são: "As lésbicas são doentes" $(\mathrm{M}=1.44$, $\mathrm{DP}=1.508) \mathrm{e}$ "Os homens homossexuais não devem ser autorizados a ensinar nas escolas" $(\mathrm{M}=1.47, \mathrm{DP}=1.246)$. 
TABELA IV - MÉDIAS E DESVIO-PADRÃO POR ITEM NA ESCALA DE ATITUDES FACE ÀS MULHERES LÉSBICAS E AOS HOMENS GAYS

ATL
As lésbicas simplesmente não têm lugar na nossa sociedade.

As lésbicas simplesmente não têm lugar na nossa sociedade.

A homossexualidade feminina não deve ser causa de discriminação

Média \pm DP no trabalho qualquer que seja a situação.

A homossexualidade feminina é prejudicial para a sociedade porque $\quad 2.31 \pm 2.180$ quebra com as divisões naturais entre os sexos.

As leis do país que regulam o comportamento privado das lésbicas $\quad 3.83 \pm 2.505$ devem ser menos rigorosas.

A homossexualidade feminina é um pecado.

$1.83 \pm 1.722$

$\mathrm{O}$ crescente número de lésbicas indica um declínio na moral da

$1.95 \pm 2.356$ sociedade portuguesa.

A homossexualidade feminina em si não é um problema, mas o que a sociedade faz com ela pode ser um problema.

A homossexualidade feminina é uma ameaça para muitas das nossas instituições sociais básicas.

A homossexualidade feminina é uma forma inferior de sexualidade.

$1.86 \pm 1.997$

$2.13 \pm 2.058$

$3.03 \pm 2.323$

As lésbicas são doentes.

$2.30 \pm 2.046$

$1.73 \pm 1.634$

$1.44 \pm 1.508$

$A T G$

Os casais de homens homossexuais devem ser autorizados a adotar crianças do mesmo modo que os casais heterossexuais.

Eu acho que os homossexuais masculinos são nojentos.

$4.42 \pm 2.827$

Os homens homossexuais não devem ser autorizados a ensinar nas escolas.

A homossexualidade masculina é uma perversão.

$2.25 \pm 2.021$

Tal como em outras espécies, a homossexualidade masculina é uma expressão natural da sexualidade dos homens.

Se um homem tem sentimentos homossexuais, deverá fazer de tudo o que possa para os superar.

Eu não ficaria muito chateado se soubesse que um filho meu é

$1.47 \pm 1.246$

$1.87 \pm 1.779$

$3.31 \pm 2.501$ homossexual.

O comportamento sexual entre dois homens é simplesmente errado.

$2.23 \pm 1.984$

A ideia do casamento entre homossexuais do sexo masculino

$4.38 \pm 2.808$ parece-me ridícula.

A homossexualidade masculina é meramente um estilo de vida

$2.07 \pm 1.906$

$2.55 \pm 2.424$

diferente que não deve ser condenado.

$3.09 \pm 2.802$

FONTE: elaboração própria, adaptado (ALVES, 2013). 
Ao observar a Tabela $\mathrm{V}$, verificamos que a média do valor obtido na escala das atitudes face a mulheres lésbicas e a homens gays (ATLG) foi de 2.50, DP = 1.196 (amplitude de 1 a 6.80). Analisando as subescalas individualmente, na escala de homonegatividade face às mulheres lésbicas (ATL) a média foi de 2.27, DP = 1.174, e na escala em relação aos homens gays (ATG) foi de 2.78, DP = 1.431.

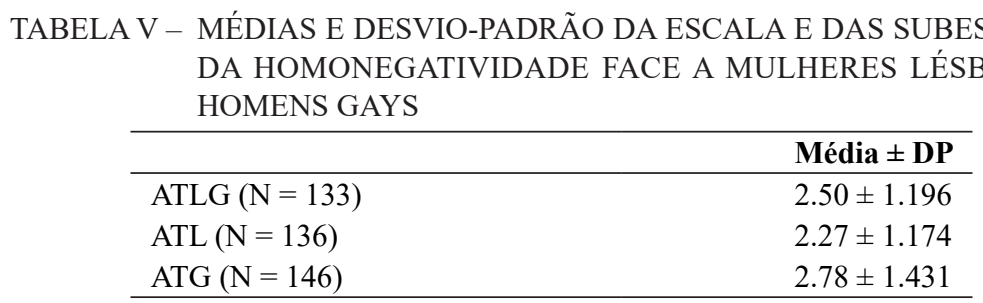

FONTE: elaboração própria, adaptado (ALVES, 2013).

A análise da frequência dos valores médios obtidos nas duas subescalas mostrou que a maioria dos/as estudantes universitários/as têm atitudes moderadamente negativas face às mulheres lésbicas $(67.6 \%)$ e aos homens gays $(71.2 \%)$, e o mesmo acontece no conjunto das duas subescalas (71.4\%) (Tabela VI).
TABELA VI - FREQUÊNCIA E PERCENTAGEM DAS MÉDIAS DOS NÍVEIS DE HOMONEGATIVIDADE NA ESCALA E SUBESCALAS FACE A MULHERES LÉSBICAS E HOMENS GAYS

\begin{tabular}{lrc}
\hline & f & $\mathbf{\%}$ \\
\hline$A T L G$ & 16 & 12.0 \\
Atitudes levemente negativas & 95 & 71.4 \\
Atitudes moderadamente negativas & 22 & 16.5 \\
Atitudes extremamente negativas & & \\
$A T L$ & 20 & 14.7 \\
Atitudes levemente negativas & 92 & 67.6 \\
Atitudes moderadamente negativas & 24 & 17.6 \\
Atitudes extremamente negativas & & \\
$A T G$ & 18 & 12.3 \\
Atitudes levemente negativas & 104 & 71.2 \\
Atitudes moderadamente negativas & 24 & 16.4 \\
Atitudes extremamente negativas &
\end{tabular}

Nota: ATLG: Atitudes levemente negativas $<1.30$; moderadamente negativas 1.30-3.70; extremamente negativas $>3.70$; ATL: Atitudes levemente negativas $<1.10$; moderadamente negativas 1.10 -3.44 ; extremamente negativas $>3.44$; ATG: Atitudes levemente negativas $<1.35$; moderadamente negativas $1.35-4.21$; extremamente negativas $>4.21$

FONTE: elaboração própria, adaptado (ALVES, 2013). 
De modo a compreender se existe correlação entre as duas subescalas Atitudes face a mulheres lésbicas (ATL) e Atitudes em relação a homens gays (ATG) - foi calculado o coeficiente de correlação de Pearson. O resultado dessa correlação permite verificar uma correlação estatisticamente significativa e fortemente positiva entre as duas subescalas $(r=.73, p=0)$, indicando que as atitudes negativas face a mulheres lésbicas estão positivamente correlacionadas com as atitudes negativas face a homens gays.

\section{Niveis de homonegatividade em função das características sociodemográficas}

Identificados os níveis de homonegatividade dos/as estudantes universitários/as do primeiro ano dos mestrados em ensino e em educação, pretendemos verificar se existem ou não diferenças nas atitudes negativas face a mulheres lésbicas e homens gays em função das características sociodemográficas dos/ as inquiridos/as.

Na Tabela VII, estão apresentados os dados relativos à homonegatividade face às mulheres lésbicas e aos homens gays em função do sexo dos/as estudantes universitários/as. No que concerne às atitudes face às mulheres lésbicas (ATL), observou-se que o facto de ser do sexo masculino $(\mathrm{M}=2.29, \mathrm{DP}=1.1311)$ ou feminino $(\mathrm{M}=2.26, \mathrm{DP}=1.115)$ não condiciona o nível de homonegatividade $(t(134)=0.135, p=.893)$. No entanto, existem diferenças significativas entre os/as inquiridos do sexo masculino $(\mathrm{M}=3.20, \mathrm{DP}=1.824)$ e do sexo feminino $(\mathrm{M}=2.59, \mathrm{DP}=1.178)$ ao nível das atitudes negativas face a homens gays, $t$ $(144)=2.443, p=.016$, ou seja, os estudantes universitários revelam uma maior homonegatividade do que as estudantes universitárias.

TABELA VII -MÉDIAS E DESVIO-PADRÃO DA HOMONEGATIVIDADE FACE ÀS MULHERES LÉSBICAS E HOMENS GAYS EM FUNÇÃO DO SEXO

\begin{tabular}{lrc}
\hline & \multicolumn{1}{c}{ ATL } & \multicolumn{1}{c}{ ATG } \\
\cline { 2 - 3 } Sexo & \multicolumn{1}{c}{ Média \pm DP } & Média \pm DP \\
\hline Masculino $(\mathrm{N}=45)$ & $2.29 \pm 1.1311$ & $3.20 \pm 1.824$ \\
Feminino $(\mathrm{N}=106)$ & $2.26 \pm 1.115$ & $2.59 \pm 1.178$ \\
\hline
\end{tabular}

FONTE: elaboração própria, adaptado (ALVES, 2013).

A análise inferencial da idade dos/as estudantes universitários/as, através da ANOVA, relativamente às atitudes negativas face a mulheres lésbicas e a homens gays, mostrou a inexistência de diferenças estatisticamente significativas $\left(F_{\mathrm{ATL}}(5,130)=2.033, p=.078 ; F_{\mathrm{ATG}}(5,140)=0.452, p=.811\right)$. De igual modo, 
em função da variável estado civil, quer a homonegativade face às mulheres lésbicas $(F=(3,132)=0.368, p=.776)$ quer face aos homens gays $(F=(3,132)$ $=0.368, p=.776)$ não são reveladas diferenças estatisticamente significativas para os/as estudantes universitários/as inquiridos/as.

$\mathrm{Na}$ análise dos resultados, através da ANOVA, verificou-se a existência de diferenças estatisticamente significativas nas atitudes negativas face às mulheres lésbicas em função do curso de mestrado frequentado $(F=(11,124)=2.064, p$ $=.028)$. Nesse sentido, a observação da Tabela VIII, permite-nos verificar que os cursos nos quais os/as estudantes universitários/as revelaram maiores níveis de homonegatividade face às mulheres lésbicas foram o mestrado em ensino de informática $(\mathrm{M}=3.16, \mathrm{DP}=1.626)$ e mestrado em ensino de matemática no $3^{\circ}$ ciclo do ensino básico e no ensino secundário $(\mathrm{M}=3.00$, $\mathrm{DP}=1.589)$.

TABELA VIII -MÉDIAS E DESVIO-PADRÃO DAS ATITUDES NEGATIVAS FACE ÀS MULHERES LÉSBICAS EM FUNÇÃO DO CURSO

\section{Curso}

Ensino de Educação Física nos Ensinos Básico e Secundário $(\mathrm{N}=12)$

Ensino de Música $(\mathrm{N}=18)$

Educação - Mediação Educacional e Supervisão na Formação $(\mathrm{N}=13)$

Ensino de Português no $3^{\circ}$ Ciclo do Ensino Básico e Ensino

Secundário e de Espanhol nos Ensinos Básico e Secundário $(\mathrm{N}=15)$

Ensino de Inglês e de Espanhol no $3^{\circ}$ Ciclo do Ensino Básico e no

Ensino Secundário $(\mathrm{N}=11)$

Ensino de Biologia e de Geologia no $3^{\circ}$ Ciclo do Ensino Básico e no

Ensino Secundário $(\mathrm{N}=12)$

Educação - Formação, Trabalho e Recursos Humanos ( $\mathrm{N}=18)$

Ensino de História e de Geografia no $3^{\circ}$ Ciclo do Ensino Básico e no

Ensino Secundário $(\mathrm{N}=8)$

Ensino de Filosofia no Ensino Secundário $(\mathrm{N}=10)$

Ensino de Matemática no $3^{\circ}$ Ciclo do Ensino Básico e no Ensino

Secundário $(\mathrm{N}=11)$

Ensino de Informática (N 11)

Educação - Educação de Adultos e Intervenção Comunitária $(\mathrm{N}=12)$
ATL

Média \pm DP

$2.87 \pm 1.279$

$2.26 \pm 1.194$

$2.55 \pm 0.958$

$1.86 \pm 0.878$

$1.92 \pm 1.066$

$2.41 \pm 1.302$

$1.90 \pm 0.857$

$1.80 \pm 0.689$

$1.73 \pm 0.828$

$3.00 \pm 1.589$

$3.16 \pm 1.626$

$1.84 \pm 0.891$

FONTE: elaboração própria, adaptado (ALVES, 2013).

No entanto, atendendo à subescala da homonegatividade face a homens gays não existem diferenças a nível do curso de mestrado, $F(11,134)=1.295$, $p=0.234$. 
Ao analisar as distribuições das médias da homonegatividade em função da religião, os resultados mostraram que os católicos apresentaram maiores níveis de homonegatividade $\left(\mathrm{M}_{\mathrm{ATL}}=2.44, \mathrm{DP}=1.209 ; \mathrm{M}_{\mathrm{ATG}}=3.02, \mathrm{DP}=1.451\right)$ do que os/as estudantes universitários/as com outra religião não cristã $\left(\mathrm{M}_{\mathrm{ATL}}=1.60\right.$, $\left.\mathrm{DP}=0.707 ; \mathrm{M}_{\mathrm{ATG}}=1.75, \mathrm{DP}=0.636\right)$, com outra religião cristã $\left(\mathrm{M}_{\mathrm{ATL}}=2.20\right.$, $\left.\mathrm{DP}=0.566 ; \mathrm{M}_{\mathrm{ATG}}=1.50, \mathrm{DP}=0.707\right)$ e sem religião $\left(\mathrm{M}_{\mathrm{ATL}}=1.35, \mathrm{DP}=0.320\right.$; $\left.\mathrm{M}_{\mathrm{ATG}}=1.730, \mathrm{DP}=0.677\right)$. Desse modo, os resultados da ANOVA revelaram a existência de diferenças estatisticamente significativas, tanto no que concerne às atitudes negativas face às mulheres lésbicas $(F(3,132)=5.67, p=.001)$ como aos homens gays $(F(3,142)=6.82, p=0)$.

Por último, observamos se o grau de religiosidade dos/as inquiridos/as influenciava os níveis de homonegatividade, tendo-se concluído que não existem diferenças ao nível das atitudes negativas face a mulheres lésbicas $(F(6,125)$ $=2.09, p=.059)$ nem face aos homens gays $(F(6,134)=2.09, p=.059) \mathrm{em}$ função do grau de religiosidade.

\section{Considerações finais}

Os resultados mostram que os/as estudantes universitários/as revelam atitudes moderadamente negativas, tanto para as mulheres lésbicas como para os homens gays, sendo esses resultados consistentes com outros estudos que demonstram que as atitudes dos/as estudantes universitários/as continuam a ser negativas (LACERDA et al., 2002; MORGAN, 2003; ALDERSON et al., 2009; GATO et al., 2010; NOTA, 2012). Contudo, apesar desses resultados, é necessário referir que a sociedade se encontra cada vez mais consciente que atitudes e comportamentos discriminatórios levantam sanções sociais, o que por sua vez nos faz perspetivar que a desejabilidade social constitua uma causa subjacente a estas atitudes moderadamente negativas. Isto porque, mesmo que a maioria dos itens apresentem valores médios de baixa homonegatividade, quando os itens apontam para a adoção de crianças por casais homossexuais homens ou para a possibilidade de ter um filho gay, os/as estudantes universitários/as revelam maiores índices de homonegatividade.

Para além dessas evidências, a análise dos resultados permitiu perceber que existem algumas características sociodemográficas que influenciam as atitudes negativas face às mulheres lésbicas e aos homens gays. O sexo é a variável que influencia as atitudes negativas face aos homens gays, já que os inquiridos do sexo masculino têm atitudes mais negativas do que as do sexo feminino. Por outro lado, o curso de mestrado que os/as inquiridos/as frequentam influencia 
as atitudes negativas face às mulheres lésbicas, sendo que os mestrados em ensino de informática e em ensino de matemática no $3^{\circ}$ ciclo do ensino básico e no ensino secundário apresentam diferenças estatisticamente significativas em comparação com os outros mestrados. A variável sociodemográfica que influencia, quer as atitudes negativas face às mulheres lésbicas quer aos homens gays, é a religião, isto porque os/as católicos/as revelam maiores níveis de homonegatividade do que aqueles/as sem religião.

Por outro lado, a idade, o estado civil e o grau de religiosidade não foram variáveis determinantes para explicar as atitudes homonegativas dos/as estudantes universitários/as, uma vez que não foram observadas diferenças estatisticamente significativas entre os níveis de homonegatividade e essas variáveis sociodemográficas.

As conclusões deste estudo mostram que os/as estudantes universitários/ as podem mascarar os seus preconceitos, levando-os/as a manifestar atitudes communente denominadas como politicamente corretas ou socialmente desejáveis, mesmo que não se elimine a existência de preconceitos subtis ou internalizados, o que corrobora com os estudos de Morrison e Morrison (2002) que se propuseram a denominar os comportamentos intolerantes face às mulheres lésbicas e aos homens gays como homonegatividade moderna. Segundo esses autores, a homonegatividade moderna assenta em três ideias-chave: as atitudes e comportamentos discriminatórios face à homossexualidade já não existem; as mulheres lésbicas e os homens gays exigem direitos ou mudanças sociais desnecessárias; as mulheres lésbicas e os homens gays colocam demasiada ênfase na sua orientação sexual, acabando por se auto-excluirem da cultura dominante.

Face ao enunciado, é urgente a criação de condições para que os/as estudantes universitários/as, durante a sua formação (académica), reflitam sobre as suas atitudes face à homossexualidade e aprendam a desenvolver processos educativos que incluam a promoção do respeito e a convivência saudável com a diversidade sexual e a defesa dos direitos humanos. Assim, por se acreditar que a transformação social e o exercício da cidadania plena não advém de um decreto estatal, pretendemos o desenvolvimento de agentes de formação e mudança, em prol do combate à homonegatividade, permitindo "melhorar a compreensão mútua entre pessoas diferentes, de criação de ligações mais fortes entre indivíduos dentro de uma comunidade, de procura de melhores formas de relacionamento" (BONAFÉ-SCHMITT, 2010, p. 67). É importante que este tipo de relações e intercâmbios se estabeleça também com a comunidade local, ou seja, ao conseguirmos aproximar as pessoas e os grupos da mesma comunidade, no sentido de trabalhar para a alteração de algumas conceções e de promover a compreensão e valorização da diversidade e das formas de estar na base de uma cidadania ativa, estar-se-á perante um desenvolvimento local que acarretará a tão almejada transformação cultural. 


\section{REFERÊNCIAS}

ALDERSON, K. G.; ORZECK T. L.; MCEWEN, S. C. Alberta High School Counsellors' Knowledge of Homosexuality and Their Attitudes Toward Gay Males. Journal of Education 32, 87-117, 2009.

ALVES, R. Prevenção da Homonegatividade: um processo de mediação sociocultural na educação em sexualidade na Biblioteca Lúcio Craveiro da Silva. 2013. Dissertação (Mestrado) - Universidade do Minho, Braga, 2013.

BONAFÉ-SCHMITT, J-P. Da mediação de bairro à mediação escolar: a outra mediação social. In: CORREIA, J. A.; SILVA, A. M. C. (Orgs.). A Mediação: (D)os contextos e (D)os atores. Porto: Edições Afrontamento, 2010. p. 46-58.

GATO, J.; LEME, V.; LEME, A. Atitudes relativamente à homossexualidade em Portugal e no Brasil, Fazendo género, 9, 1-11, 2010.

GATO, J.; CARNEIRO, N. S.; FONTAINE, A. M. Contributo para uma revisitação histórica e crítica do preconceito contra as pessoas não heterossexuais. Crítica e Sociedade: Revista da Cultura Política, 1(1), 139-167, 2011.

HEREK, G. M. Heterosexuals' attitudes toward lesbians and gay men: correlates and gender differences. The Journal of Sex Research, 25, 451-477, 1998.

JUNQUEIRA, R. D. Diversidade sexual e homofobia. In: XAVIER-FILHA, C. (Org.). Educação para a sexualidade, para a equidade de género e para a diversidade sexual. Campo Grande: UFMS, 2009. pp.111-142.

LACERDA, M.; PEREIRA, C.; CAMINO, L. Um estudo sobre as formas de preconceito contra homossexuais na perspectiva das representações sociais. Psicologia Reflexão e Crítica, 15(1), 165-178, 2002.

MORGAN, D. J. Knowledge and Attitudes of Preservice Teachers toward students who are gay, lesbian, bisexual or transgendered. 2003. Dissertation prepared for the degree of Doctor of Philosophy, special education. Texas: University of North Texas, 2003.

MORRISON, M. A.; MORRISON, T. G. Development and validation of a scale measuring modern prejudice toward gay men and lesbian women. Journal of Homosexuality, 43, 15-37, 2002.

NOGUEIRA, C.; OLIVEIRA, J. M. Um olhar da psicologia feminista crítica sobre os direitos humanos de pessoas LGBT. In: NOGUEIRA, C.; OLIVEIRA, J. M. (Orgs.). Estudo sobre a discriminação em função da orientação sexual e da identidade de gênero. Lisboa: Comissão para a Cidadania e a Igualdade de Gênero, 2010. p. 9-17.

NOTA, J. M. Conhecimentos, atitudes e representações face às homossexualidades entre os futuros professores de Biologia para o ensino secundário geral. 2012. Dissertação (Mestrado em Educação: ensino da Biologia) - Universidade Pedagógica, Maputo, 2012.

Texto Recebido em 13 de março de 2018.

Texto aprovado em 13 de maio de 2018. 